\title{
Mesoblastic nephroma contains fibronectin but lacks laminin
}

\author{
S KUMAR, HB MARSDEN, T CARR, R KODET \\ From the Christie Hospital, Manchester
}

SUMMARY Non-metastatic mesoblastic nephromas from four young children were shown to contain fibronectin but not laminin using an immunoperoxidase staining procedure. In contrast, one metastasising spindle celled sarcomatous tumour from a neonate was laminin positive. During embryogenesis primitive nephrogenic mesenchyme contains only fibronectin and no laminin; metanephric blastema (permanent kidney) is positive for laminin. The staining for fibronectin and laminin may help to ascertain the histogenesis of different types of renal tumour.

Renal malignancies account for about $8 \%$ of childhood solid tumours, the commonest being Wilms' tumour, which is often metastatic and is treated by chemotherapy or radiotherapy or both. The prognosis of Wilms' tumour is influenced by histology, age, stage, and so on.' Until 1973 mesoblastic nephroma was not distinguished from Wilms' tumour, ${ }^{2}$ but there is now overwhelming clinicopathological evidence to justify fully its separation. ${ }^{34}$ Mesoblastic nephroma is a tumour of infancy and early childhood and carries an excellent prognosis. Of 17 mesoblastic nephromas studied by us, all of them were found in children under the age of two years. ${ }^{5}$ In fact the oldest child was 21 months and two specimens were from neonates and a further two from premature babies of 28 and 35 weeks' gestation. None of the 17 mesoblastic nephromas was metastatic. These days the only treatment given to children with mesoblastic nephroma is nephrectomy - that is, no chemotherapy or radiotherapy.

Apart from collagen, two major components of the extracellular matrix are fibronectin and laminin. Fibronectin is a large glycoprotein which is present on the surface of normal cells but is either absent or present in considerably reduced amounts on malignant and transformed cells. Generally, the amount of fibronectin correlates inversely with tumorgenicity and ability to metastasise. ${ }^{6}$ Laminin is a basement membrane glycoprotein, the function of which has not yet been clearly established. It is believed to be important in the differentiation of the kidney. The

Accepted for publication 8 January 1985 published work suggests that during embryogenesis fibronectin and laminin are absent in the earliest morula conceptus. ${ }^{7}$ Fibronectin is first detectable when the mesoderm appears; it is present in the primitive nephrogenic mesenchyme. Laminin, on the other hand, is absent from primitive nephrogenic mesenchyme and is first detected in metanephric blastema. These two glycoproteins might therefore act as markers in determining the embryonic origin of kidney tumours. A popular belief is that all kidney tumours arise from metanephric blastema. The results of the present study, however, suggest that non-metastatic mesoblastic nephroma may originate from more primitive nephrogenic mesenchymal cells and metastatic mesoblastic nephroma from metanephric blastema.

\section{Material and methods}

\section{TISSUES}

The mesoblastic nephromas studied were biopsy specimens from Manchester, fixed in $10 \%$ formalin, and paraffin embedded for routine histology. The tissues were sectioned at $5 \mu \mathrm{m}$ thickness. A renal tumour (formalin fixed and paraffin embedded) from Czechoslovakia was also studied and will be referred to as the Prague case.

\section{REAGENTS}

\section{Antibodies}

Rabbit antihuman fibronectin, swine antirabbit immunoglobulin, and peroxidase-rabbitantiperoxidase were purchased from Dakopatts (Mercia-Brocades Ltd, UK). Rabbit antibody to mouse laminin known to cross react with human 
laminin was bought from Bethesda Research Laboratories UK, Cambridge. All sera were used at a dilution of $1 / 40$ in $0.01 \mathrm{M}$ phosphate buffered saline (PBS), $\mathrm{pH} 7 \cdot 4$.

\section{Enzymes}

Pepsin (Sigma P7012, Dorset UK) was used at 0.4\% wt/vol in $0.01 \mathrm{M} \mathrm{HCl}$. Testicular hyaluronidase (Miles Scientific, UK) was used at a concentration of $1 \mathrm{mg} / \mathrm{ml}$ in PBS.

\section{IMMUNOPEROXIDASE STAINING PROCEDURE}

The peroxidase-antiperoxidase staining procedure was used to localise fibronectin and laminin. ${ }^{8}$ Wax embedded tissues were deparaffinised in two changes of xylene and taken to alcohol. Endogenous peroxidase was inhibited by treating with $0.5 \%$ $\mathrm{H}_{2} \mathrm{O}_{2}$ in methanol, and the sections were washed well in tap water, placed in distilled water, treated with either pepsin or hyaluronidase, and washed three times in PBS. Next, sections were treated with antifibronectin or antilaminin and washed three times in PBS; swine antirabbit immunoglobulin was added and the sections again washed in PBS; and finally PAP complex was added, followed by another three washes in PBS. Colour was developed using diaminobenzidine (Sigma) and the sections were counterstained with haematoxylin, dehydrated, cleared, and mounted.

To confirm the specificity of the staining procedure three normal kidneys were stained using immune antisera-namely, antifibronectin and antilaminin-or normal rabbit serum.

\section{Results}

Neither fibronectin nor laminin could be shown before enzymatic treatment of tissue sections. That the use of pepsin had no adverse effect on fibronectin and laminin was excluded by treating some of the sections with hyaluronidase instead of pepsin. Comparison of stained preparations after pepsin and hyaluronidase treatment showed no detectable dif- ference in either the distribution or the intensity of the staining reaction. In normal kidneys, as expected, fibronectin and laminin were localised to basement membranes of blood vessels and tubules. In addition, fibronectin was also present in glomerular capillaries. No staining was seen in either tumour or normal kidney when treated with normal rabbit serum.

Four mesoblastic nephromas were studied (Table). Histologically, CTR34/61 was a hypercellular mesoblastic nephroma with nuclear polymorphism. The spindle shaped cells were shorter than those of case 2 (CTR2/64) and contained mitotic figures. Many parts of the tumour showed no staining with fibronectin antiserum, whereas other parts had strong fibrillar network staining patterns. No laminin was seen in tumour cells, but basement membranes of blood vessels and tubules showed strong staining for laminin.

CTR2/64 was a normocellular mesoblastic nephroma, which was made up of uniform spindle cells and occasional embedded renal tubules. In most areas spindle cell bodies, basement membrane, and even fibrillary extensions of cell membranes were strongly positive for fibronectin (Fig. 1). There were occasional patches which stained lightly for fibronectin. Laminin was absent in the tumour tissue, but basement membranes of blood vessels and tubules stained intensely (Fig. 2).

CTR66/70 and CTR45/71 were both hypercellular mesoblastic nephromas. CTR66/70 contained hypocellular areas with islands of precartilage and extended through the renal capsule into the adjacent perirenal fat and adrenal capsule. Fibronectin in these two tumours was distributed as a fibrillar network, which varied in intensity from area to area. Laminin could not be shown in either tumour except in basement membranes of blood vessels and glomeruli.

The Prague case was from a neonate born with bilateral kidney tumours, who died with widespread metastasis at the age of 4 months (Table). The fascicular arrangement of the cells in this tumour

Details of the four mesoblastic nephromas and a Prague case used to localise fibronectin and laminin by an immunoperoxidase method

\begin{tabular}{|c|c|c|c|c|c|c|c|c|c|}
\hline \multirow[t]{2}{*}{ Case no } & \multirow[t]{2}{*}{ CTR No } & \multirow[t]{2}{*}{$\begin{array}{l}\text { Age at diagnosis } \\
\text { (mo) }\end{array}$} & \multirow[t]{2}{*}{ Sex } & \multirow[t]{2}{*}{ Side } & \multirow[t]{2}{*}{ Pathology } & \multicolumn{2}{|c|}{$\begin{array}{l}\text { Results of immunoperoxidase } \\
\text { staining with }\end{array}$} & \multirow[t]{2}{*}{ Outcome } & ర్ \\
\hline & & & & & & Fibronectin & Laminin & & \\
\hline
\end{tabular}

\begin{tabular}{|c|c|c|c|c|c|c|c|c|}
\hline $\begin{array}{l}1 \\
2\end{array}$ & $\begin{array}{r}34 / 61 \\
2 / 64\end{array}$ & $\begin{array}{l}3 \\
0\end{array}$ & $\begin{array}{l}\mathbf{F} \\
\mathbf{M}\end{array}$ & $\mathbf{L}$ & $\begin{array}{l}\text { Hypercellular } \\
\text { Typical-uniform } \\
\text { spindle cells }\end{array}$ & + & - & $\begin{array}{l}\text { Alive and well after } 22 \text { years } \\
\text { Dead after } 7 \text { days of septicaemiar } \\
\text { No residual tumour }\end{array}$ \\
\hline 3 & $66 / 70$ & 6 & $\mathbf{F}$ & $\mathbf{L}$ & $\begin{array}{l}\text { Mixed-normal and } \\
\text { hypercellular }\end{array}$ & + & - & Alive and well after 13 years \\
\hline $\begin{array}{l}4 \\
5\end{array}$ & $\begin{array}{l}45 / 71 \\
\text { Prague case }\end{array}$ & 2 & $\begin{array}{l}\mathbf{M} \\
\mathbf{F}\end{array}$ & $\begin{array}{l}\mathbf{R} \\
\text { Bilateral }\end{array}$ & $\begin{array}{l}\text { Hypercellular } \\
\text { Herringbone }\end{array}$ & + & $\overline{+}$ & $\begin{array}{l}\text { Alive and well after } 12 \text { years } \\
\text { Dead after } 4 \text { months with } \\
\text { widespread metastasis }\end{array}$ \\
\hline
\end{tabular}



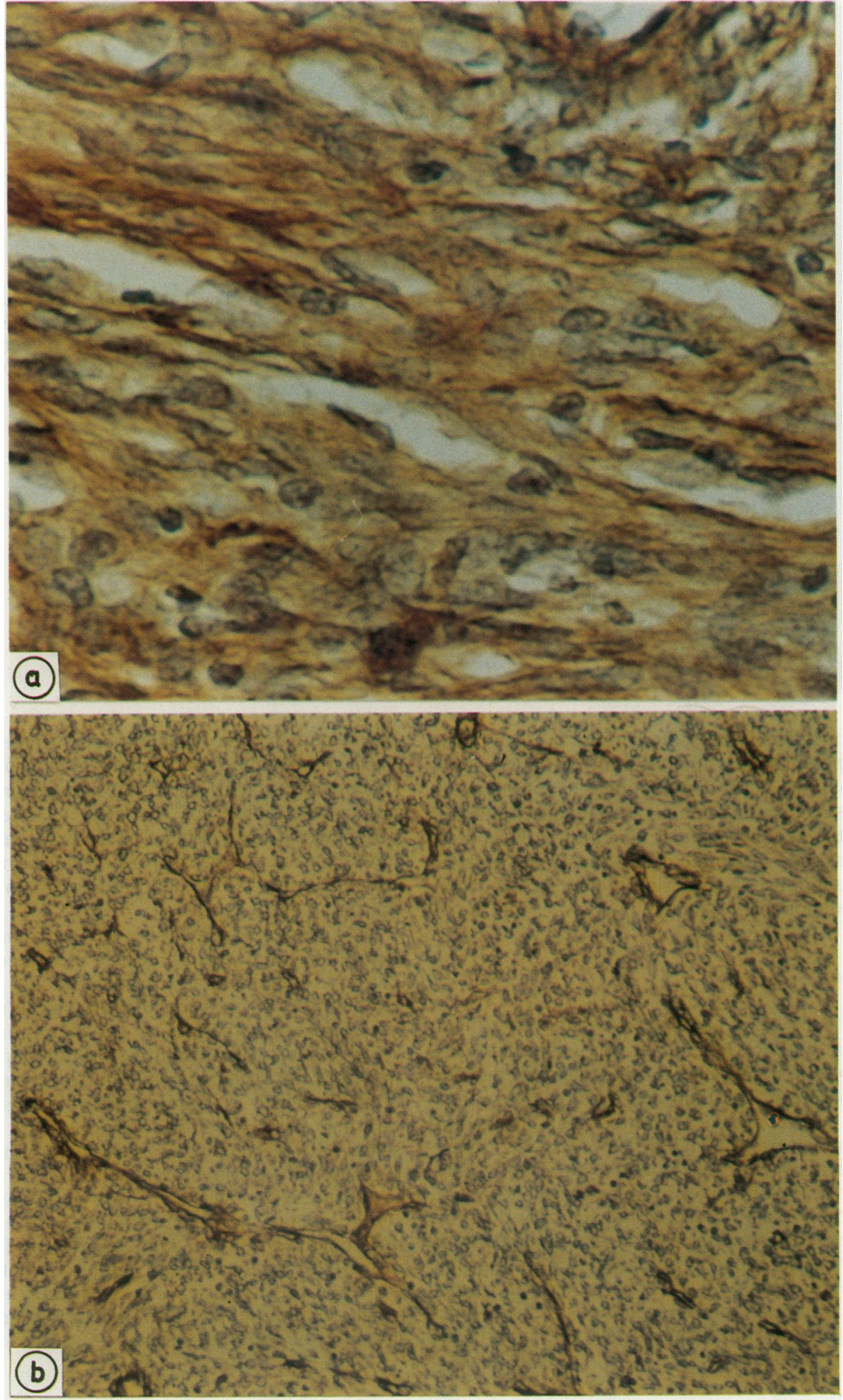


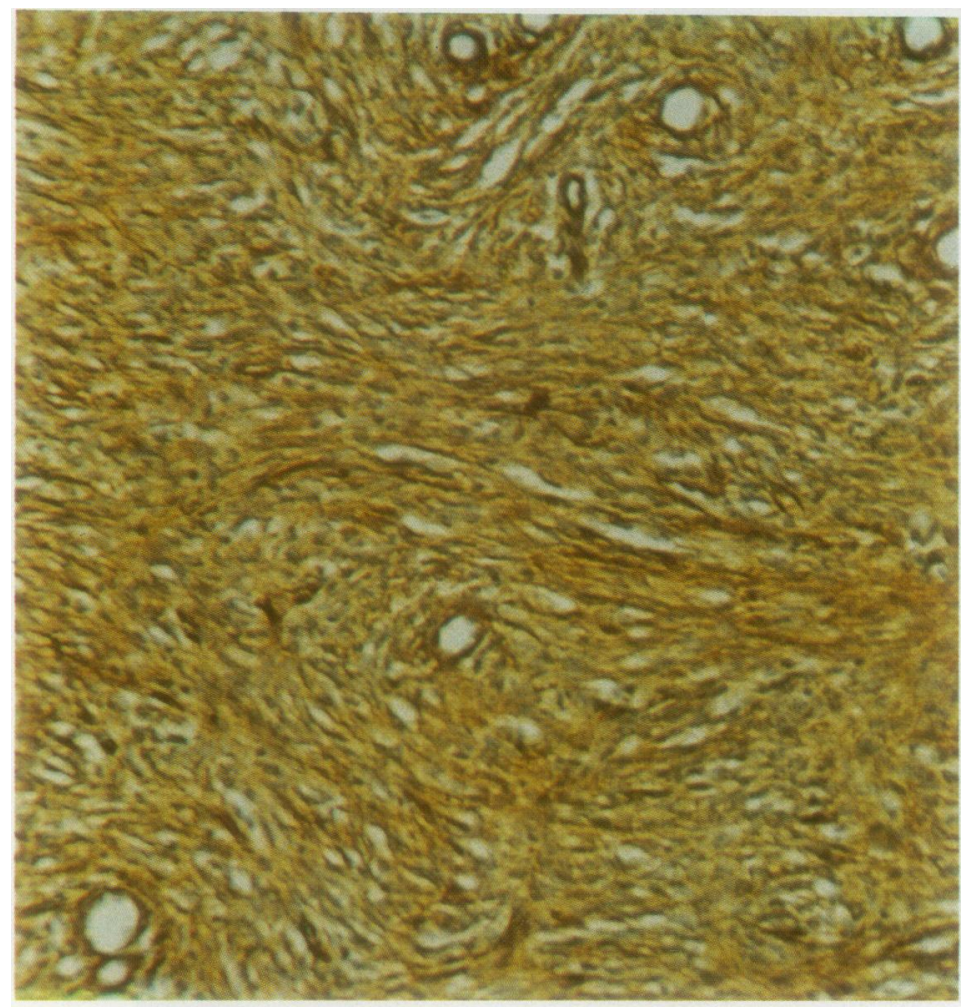

Fig. 2 Laminin: mesoblastic nephroma. The spindle cells are negative but positive staining can be seen in the blood vessel wall.

showed a herringbone pattern and the cells were more hyperchromatic and less uniform than in cellular mesoblastic nephroma. Staining with fibronectin showed some positive reactivity. The distribution of fibronectin was pericullular and not diffuse cytoplasmic as seen in spindle cells of mesoblastic nephroma. Laminin showed positivity with diffuse staining of individual cells.

\section{Discussion}

The results show that mesoblastic nephromas contain fibronectin but lack laminin. It is possible that cells of mesoblastic nephromas produce laminin but fail to incorporate it into their cell surface matrix. For instance, Hayman et al $^{y}$ reported that fibronectin and laminin were detectable in normal rat kidney cells but both were absent from the surface of virally transformed rat kidney cells. Their studies, however, showed that transformed rat kidney cells do synthesise and release both laminin and fibronectin in tissue culture supernatant but fail to deposit them as an insoluble matrix. From their extensive experimental data the authors concluded the following: "Failure of the transformed cells to incorporate fibronectin into an insoluble cell surface matrix is not a consequence of a demonstrable change in the functional characteristics of the fibronectin molecule nor in the ability of the cells to interact with fibronectin. It may depend on an as yet unidentified interaction at the cell surface. Similar interactions may be needed for the deposition of laminin into the matrix."

As regards histogenesis, the term mesoblastic nephroma, although generally accepted, is not entirely suitable as differentiated squamous epithelium is an occasional feature in this neoplasm. We believe that the tumour arises from fibronectin positive and laminin negative primitive, potentially nephrogenic blastema and not from metanephric blastema which is laminin positive. ${ }^{7}$ This observation may have prognostic value as there are occasional examples in the published work of metastasising mesenchymal nephromas of infancy. ${ }^{10}$ " Whether or not these neoplasms are true mesoblastic nephromas remains a problem which is important in the differential diagnosis. Our results of differential staining for fibronectin and laminin of metastasising and non-metastasising mesenchymal nephromas suggest that these two differ in their histogenesis and may thus be separate entities. 


\section{References}

' Marsden HB, Lawler W, Carr TF, Kumar S. A scoring system for Wilms tumor: pathological study of the second Medical Research Council (MRC) trial. Int J Cancer 1984;33:365-8.

${ }^{2}$ Bolande RP. Congenital mesoblastic nephroma of infancy. Perspect Pediatr Pathol 1973;1:227-50.

${ }^{3}$ Gonzalez-Crussi F, Sotelo-Auila C, Kidd JM. Mesenchymal renal tumours in infancy: a reappraisal. Human Pathol 1981;12:646-57.

4 Marsden HB, Lawler W. Primary renal tumours in the first year of life. Virchows Arch (Pathol Anat) 1983;399:1-9.

${ }^{5}$ Kumar S, Marsden HB, Calabuig MC. Childhood kidney tumours: in vitro studies and natural history. Virchows Arch (Pathol Anat) 1984;405:95-111.

- Nicholson G. Cancer metastasis: organ colonization and the cell-surface properties of malignant cells. Biochem Biophys 1982;695: 113-76.

${ }^{7}$ Gonzalez-Crussi F, Franklin WA. Embryologic considerations. In: Gonzalex-Crussi F, ed. Wilms' tumor (nephroblastoma) and related renal neoplasms of childhood. Florida, USA: CRC Press Inc, 1984:8-18.

${ }^{8}$ Polak JM, Noorden SV, eds. Immunocytochemistry: practical applications in pathology and biology. Bristol: Wright PSG, 1983:11-42.

- Hayman CG, Engvall E, Ruoslahti E. Concomitant loss of cell surface fibronectin and laminin from transformed rat kidney cells. J Cell Biol 1981;88:352-7.

${ }^{10}$ Gonzalez-Crussi, ed. Wilms' tumor (nephroblastoma) and related renal neoplasms of childhood. Florida, USA: CRC Press Inc, 1984.

" Steinfeld AD, Crowley CA, O' Shea PA, Tefft M. Recurrent and metastatic mesoblastic nephroma in infancy. $J$ Clin Oncol 1984;2:956-60.

Requests for reprints to: Dr S Kumar, Christie Hospital, Wilmslow Road, Withington, Manchester M20 9BX, England. 